\title{
SUBMISSIVENESS TO HEALTH AUTHORITIES AS AN OBSTACLE TO PRACTICING EVIDENCE BASED MEDICINE
}

\author{
Ilickovic Ivana ${ }^{1}$, Jankovic M Slobodan ${ }^{2}$. \\ ${ }^{1}$ Farmegra d.o.o, 4. Jula 60, Podgorica, Montenegro \\ ${ }^{2}$ Faculty of Medical Sciences, University of Kragujevac, Serbia
}

\section{Dear Editor,}

In the Balkan countries, submissiveness to medical authorities is a widespread attitude among physicians, who consider ministries of health to be a primary source of initiative for the introduction of new knowledge and skills in medical practice [1]. To examine whether such an attitude might inhibit the practice of evidence-based medicine (EBM) by family physicians, we conducted a qualitative, semi-structured survey of a sample of family physicians in Podgorica, Montenegro. The topic of the survey interview was secondary prevention of related morbidity and mortality of patients who have experienced myocardial infarction (MI).

The interview schedule was developed through consultation with fellow clinical pharmacists and pharmacologists, and its face and content validity were checked means of using a pilot study. Eight physicians (age range: $45-57$ years; 5 males and 3 females), out of a total of 57 family physicians working in 14 state-owned primary care facilities serving 150,000 inhabitants in Podgorica, were randomly sampled and interviewed. To analyse the taped interviews, the framework approach, validated through repeat analysis, was employed.

The findings suggest that, despite the explicitness and robustness of evidence for secondary prevention of related morbidity and mortality of patients who have experienced MI and the broad availability of open-access sources of such evidence, primary care physicians in Podgorica are unaware of either effective prophylactic therapy or the evidence-based information sources. In addition, we observed a discrepancy between information that was explicitly described by interview subjects as reliable and influential (for example, CME events or journals), despite its unavailability, and extensively - used sources that prescriptions were actually based on. Physicians mostly relied on non-evidence based sources of information, such as opinion leaders, colleagues, unsystematic experience, pharmaceutical companies and uncritical internet searches [2]. Their main goals were to become "encouraged", "affirmed" and "supported", which resulted in psychological gain but did not guarantee benefits for patients. The most trustworthy information sources were regarded as national experts recognised by the heath authorities, namely, well known "professors", regardless of whether they practiced EBM.

An interesting finding of our study was unsubstantiated enthusiasm for EBM among interviewed family physicians. Although they had a false conception of research evidence, lacked retrieval and appraisal skills, practiced therapeutic conservatism, and relied on "shortcuts" in interpreting research studies, they nevertheless highly valued the role of research evidence in clinical decision-making [2]. EBM appeared to them as an ideal that is not applicable in everyday work. They complained of many contextual and individual barriers: unavailability, inaccessibility and a lack of organised dissemination of unbiased, up-to-date information. In addition, they cited reluctance to change practice patterns and practical constraints. However, they did not perceive themselves as main sources of change but expected initiatives from outside sources, primarily the state and its responsible officers. They expected educational, organisational, and structural interventions, which will "tell them what to do".

Passivism, conservatism and submissiveness to health authorities were also observed in studies of primary care physicians' attitudes towards EBM conducted in other countries with authoritarian social structures [3, 4]. Instead of directly using numerous free EBM resources available on the Internet for self-education and implementing this knowledge into their practices, the majority of primary care physicians in such countries expect to be offered formal education organised and conducted by health authorities and their "experts" [3, 4, 5]. Although they have heard of EBM and view it positively, primary care physicians generally lack sufficient initiative to alter their routine behaviour and make significant changes. 


\section{REFERENCES}

1. Jakovljevic MB. Resource allocation strategies in Southeastern European health policy. Eur J Health Econ 2013; 14(2): 153-9.

2. Đorđević ND, Janković SM. Characteristics of decisionmaking process during prescribing in general practice. Vojnosanitetski pregled 2006; 63(3): 279-285.

3. Al-Ansary LA, Khoja TA.The place of evidence-based medicine among primary health care physicians in
Riyadh region, Saudi Arabia. Fam Pract 2002; 19(5): 537-42.

4. Al Omari M, Khader Y, Jadallah K, Dauod AS, AlShdifat AA, Khasawneh NM. Evidence-based medicine among hospital doctors in Jordan: awareness, attitude and practice. J Eval Clin Pract 2009; 15(6): 1137-41.

5. Sackett D, William MC, Rosenberg JA, Muir G, Haynes B, Richardson S. 1996 Evidence based medicine: what it is and what it isn't. BMJ 1996; 312: 71-72. 